\title{
Soil Variables Associated with Sudden Death Syndrome in Soybean Fields in Iowa
}

\author{
H. Scherm, Department of Plant Pathology, University of Georgia, Athens 30602; and X. B. Yang and P. Lundeen, \\ Department of Plant Pathology, Iowa State University, Ames 50011
}

\begin{abstract}
Scherm, H., Yang, X. B., and Lundeen, P. 1998. Soil variables associated with sudden death syndrome in soybean fields in Iowa. Plant Dis. 82:1152-1157.

Sudden death syndrome, caused by Fusarium solani f. sp. glycines, has increased in prevalence in soybean production regions in the North-Central United States. Little is known about soil factors and environmental conditions that influence disease severity in this pathosystem. We studied associations between biological, chemical, and physical soil variables and severity of foliar symptoms of sudden death syndrome in nine commercial soybean fields in Iowa during 1995 and 1996. Disease was patchy in all fields, and soil samples were collected in each field along a transect that ran from a symptomless area through a diseased area. There were 25 sampling stops along each transect, separated by distances of 1.5 to $2.5 \mathrm{~m}$. At each stop, soil samples were collected and soil strength, soil moisture, and foliar disease severity (at plant growth stage R6) were measured. Soil samples were assayed for population densities of $F$. solani f. sp. glycines, cysts of the soybean cyst nematode (Heterodera glycines), and for chemical variables (soluble salts, $\mathrm{pH}$, organic matter, cation exchange capacity, and concentrations of $\mathrm{P}, \mathrm{K}, \mathrm{Ca}, \mathrm{Mg}$, $\mathrm{Mn}$, and $\mathrm{Fe}$ ). Cross-correlation analyses were carried out to test for associations between soil variables and disease severity in individual fields, while discriminant analysis was used to assess the effects of soil variables across all fields. Disease severity showed consistent associations with $F$. solani f. sp. glycines populations (strong effect) and $H$. glycines cyst counts (minor effect). Available $\mathrm{K}$ was identified as a possible disease-enhancing factor, but the magnitude of its effect was dependent on the overall K-concentrations in the fields. For example, as the median K-concentration increased, the correlation between $\mathrm{K}$ and disease decreased. None of the other soil variables showed consistent associations with disease. The results suggest that localized presence or absence of $F$. solani f. sp. glycines is the chief reason for the patchiness of sudden death syndrome in affected fields. Thus, manipulation of soil nutrient status or fertility level appears to have limited potential for reducing disease in the high-yield soybean production environment of Iowa. Instead, producers should focus on preventing the establishment or reducing populations of $F$. solani f. sp. glycines and H. glycines in their fields.
\end{abstract}

Additional keywords: Glycine max, risk assessment

Sudden death syndrome is a mid- to lateseason disease of soybean (Glycine max) caused by blue-pigmented, slow-growing strains of Fusarium solani $(17,20)$ which have recently been designated $F$. solani $\mathrm{f}$. sp. glycines $(16,18)$. Aboveground symptoms of sudden death syndrome are characterized by chlorotic and necrotic blotches of the leaves, which coalesce and cause interveinal necrotic streaks. These symptoms are generally first observed during reproductive development of the crop $(18,21)$. In severe cases, leaves and pods abscise and affected plants die prematurely. Belowground symptoms consist of root rot and crown necrosis. Yield losses around $40 \%$ have been reported from Illinois (9)

Corresponding author: H. Scherm

E-mail address: scherm@arches.uga.edu

Supported by the Iowa Soybean Promotion Board and Hatch Act and State of Iowa funds.

Accepted for publication 8 July 1998.

Publication no. D-1998-0810-01R

(C) 1998 The American Phytopathological Society and Iowa (25). Losses in the southern United States can be even greater (11).

Some progress has been made over the past few years in understanding the ecology and epidemiology of sudden death syndrome $(15,18)$. Field observations suggest that the disease is more severe in early plantings $(10,30)$, in no-till fields $(28,30)$, under irrigation $(15,25)$, and in the presence of the soybean cyst nematode (Heterodera glycines; 14,15,17). A recent study (25) showed that disease severity is strongly influenced by soil moisture and soil temperature, whereby the severity of foliar symptoms increased exponentially with increasing soil moisture. Soil temperature differentially influenced the development of root symptoms and foliar symptoms (25), with root symptoms most severe at low temperatures $\left(15^{\circ} \mathrm{C}\right)$ and foliar symptoms most severe at intermediate temperatures $\left(22\right.$ to $\left.24^{\circ} \mathrm{C}\right)$.

Despite increased research interest in sudden death syndrome, it has remained difficult to explain regional patterns, within-field patterns, and annual variations in disease based on environmental conditions, soybean growth stage, or manage- ment practices (18). This is especially true for soybean production regions in the North-Central United States, where sudden death syndrome has only been a problem for a few years $(9,13,31,32)$. Thus, more research is needed to assess the effects of soil factors and environmental conditions on incidence and severity of the disease in the field. In this study, we analyzed relationships between various biological, chemical, and physical soil variables and the severity of foliar symptom expression of sudden death syndrome in commercial soybean fields in Iowa. An abstract based on parts of this work has been published (27).

\section{MATERIALS AND METHODS}

Data collection. Based on statewide, regional, and local disease surveys (31), reports from county extension personnel, and samples submitted to the plant disease clinic at Iowa State University, commercial soybean fields with sudden death syndrome were identified during reproductive development of the crop in 1995 and 1996. Fields were visited during growth stage R6 (pods containing full-size beans at one of the four uppermost nodes; 6) for disease assessment and plant and soil sampling. Growth stage R6 was selected for the surveys because foliar symptoms were fully developed and diseased areas in the fields had reached their full spatial extent at that time. Disease was patchy in all affected fields, and fields having diseased patches with diameters of 20 to $30 \mathrm{~m}$ were selected. In 1995, six fields were sampled (fields 1 through 6 in Table 1) in eastcentral Iowa (Scott and Clinton counties) where the disease was prevalent that year. In 1996, prevalence of sudden death syndrome was very low statewide and only three fields were sampled (Table 1), two of which were in central Iowa (Webster County). In each field, disease assessments were made and soil samples were collected along a transect from a symptomless area of the field into a diseased patch and back into a symptomless area on the opposite end of the patch (Fig. 1). There were 25 sampling stops along each transect, separated by distances of 1.5 to $2.5 \mathrm{~m}$, depending on the diameter and shape of the patch. The transects were linear in most cases, and about half the sampling stops were located within the diseased patch (Fig. 1). At each stop, the following samples and measurements were collected within a radius of $0.5 \mathrm{~m}$ : (i) foliar disease severity (percent chlorotic or necrotic leaf 
area) on the five uppermost trifoliates of five plants using a Horsfall-Barratt scale (12), with defoliation assessed as $100 \%$ disease severity; (ii) five or six $2.5-\mathrm{cm}$ soil cores from 0 to $15 \mathrm{~cm}$ depth; (iii) five readings of soil strength ( 0 to $10 \mathrm{~cm}$ depth) using a cone penetrometer (2); and (iv) five readings of soil moisture using a Rapitest soil moisture meter (Luster Leaf Products, Woodstock, IL). The moisture probe, which provided readings on a scale from 0 (dry) to 10 (wet), was inserted into the soil to a depth of $5 \mathrm{~cm}$. Soil strength, as measured with the penetrometer, was standardized to a relative scale $($ maximum $=100)$ for each field to account for different moisture contents among the fields.

Soil samples were refrigerated, transported to the laboratory, and analyzed for the following variables: (i) population densities of $F$. solani f. sp. glycines; (ii) $H$. glycines cyst counts; and (iii) chemical soil variables, including soluble salt concentration, $\mathrm{pH}$, organic matter content, cation exchange capacity (CEC), and the concentrations of $\mathrm{P}, \mathrm{K}, \mathrm{Ca}, \mathrm{Mg}, \mathrm{Mn}$, and $\mathrm{Fe}$ (Table 2). All nutrient analyses were conducted by a commercial laboratory (Belmond Labs Inc., Belmond, IA). F. solani f. sp. glycines was distinguished from other forms of $F$. solani commonly associated with soybean based on cultural characteristics on potato dextrose agar $(16,17)$. Pathogenicity of representative isolates (usually three to six isolates per field) from soil and from roots of infected plants was ascertained on non-wounded 'BSR 101' soybeans in the greenhouse using published inoculation procedures (25).

Data analysis. Data were first inspected visually by plotting measured values for all variables against location along the transect (for example, Fig. 2). This allowed us to identify positive or negative associations among variables for each field. Because measured values along the transects were spatially autocorrelated for most variables, time series analysis procedures (PROC ARIMA; SAS Institute, Cary, NC) were used to calculate cross-correlation coefficients between biological, chemical, and physical soil variables and disease severity (4). The analysis was done for each field separately to determine whether significant associations were consistent across fields. $\mathrm{CEC}$ and $\mathrm{pH}$ were excluded from all analyses because they were collinear with $\mathrm{Ca}(r$ $=0.970)$ and $\mathrm{Mn}(r=-0.869)$, respectively.

Data from the nine fields were combined $(N=225)$ and samples were categorized into two groups based on foliar disease severity: no or little disease $(<10 \%)$ and moderate to severe disease $(\geq 10 \%)$. This classification resulted in approximately equal numbers of data points in the two groups. (Because of the bimodal frequency distribution of disease severity [Fig. 3], the analysis was relatively insensitive to changes in the disease severity threshold.) The soil variables listed in Table 2 were then used as predictors in stepwise discriminant analysis $(1,24,29)$ for statistical classification of the samples into the two disease severity classes. All variables were standardized to zero mean and unit variance before discriminant analysis. The differentiation between the two groups obtained by entering the selected variables was interpreted based on the magnitude and significance level of the average squared canonical correlation (ASCC), which estimates the amount of variance accounted for by classifying the observations into the two groups. Discriminant analyses were performed using the stepwise selection algorithm (PROC STEPDISC) within the SAS program li-

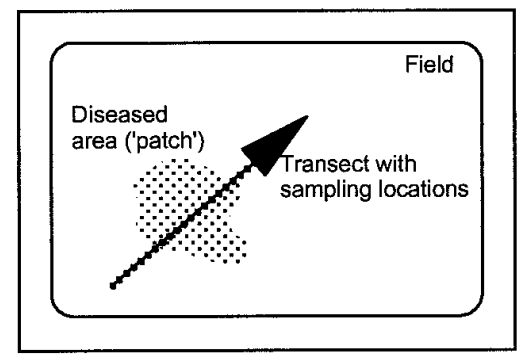

Fig. 1. Schematic representation of the sampling pattern used to collect plant and soil samples in commercial soybean fields with sudden death syndrome. Samples were collected along transects from a symptomless area of the field into a diseased patch and back into the symptomless area at the opposite end of the patch. There were 25 sampling stops along the transect, separated by distances of 1.5 to $2.5 \mathrm{~m}$.

Table 1. Characteristics of nine commercial soybean fields in which soil and plant samples were collected along transects through areas with sudden death syndrome to analyze relationships between biological, chemical, and physical soil variables and foliar disease severity

\begin{tabular}{|c|c|c|c|c|c|c|c|}
\hline \multirow[b]{2}{*}{ Field } & \multirow[b]{2}{*}{ County } & \multirow[b]{2}{*}{ Soil type } & \multirow[b]{2}{*}{ Soil texture } & \multirow[b]{2}{*}{ pH } & \multirow[b]{2}{*}{ Organic matter } & \multicolumn{2}{|c|}{ Fertility level $^{a}$} \\
\hline & & & & & & $\mathbf{P}$ & $\mathbf{K}$ \\
\hline 1 & Scott & Bolan loam & Light-medium & $6.8-7.4$ & $3.0-3.3 \%$ & Very high & Medium-very high \\
\hline 2 & Scott & Sparta loamy fine sand & Light-medium & $7.3-7.6$ & $2.4-3.0 \%$ & Very high-extremely high & High-very high \\
\hline 3 & Scott & Zook silty clay loam & Medium-very heavy & $6.5-7.0$ & $3.6-4.4 \%$ & Very high & Very high \\
\hline 4 & Scott & Richwood silt loam & Medium & $5.5-6.6$ & $3.3-4.3 \%$ & Medium-very high & High-very high \\
\hline 5 & Clinton & Garwin silty clay loam & Medium-very heavy & $6.9-7.2$ & $3.9-5.5 \%$ & Medium-extremely high & High-extremely high \\
\hline 6 & Clinton & Atterberry silt loam & Medium & $7.2-7.6$ & $3.0-3.6 \%$ & Extremely high & Very high-extremely high \\
\hline 7 & Scott & Ackmore silt loam & Medium & $7.1-7.7$ & $2.4-3.2 \%$ & High-extremely high & High-very high \\
\hline 8 & Webster & Webster silty clay loam & Medium-very heavy & $6.0-8.0$ & $4.1-6.1 \%$ & Low-very high & High-very high \\
\hline 9 & Webster & Webster silty clay loam & Heavy-very heavy & $5.8-6.6$ & $4.4-5.7 \%$ & Medium-very high & High-very high \\
\hline
\end{tabular}

${ }^{a}$ Based on soil test results for $\mathrm{P}$ and $\mathrm{K}$ in relation to $\mathrm{P}$ and $\mathrm{K}$ removal by soybeans (assumed yield: $4.4 \mathrm{~m}^{3} / \mathrm{ha}$ ).

Table 2. Methods used to determine biological, chemical, and physical characteristics of soil samples collected along transects through areas with sudden death syndrome in commercial soybean fields

\begin{tabular}{|c|c|c|c|}
\hline Variable & Method & Units & Reference \\
\hline Fusarium solani f. sp. glycines & Dilution-plating on modified & & \\
\hline populations & Nash-Snyder medium & CFU/g soil & Rupe et al. (22) \\
\hline Heterodera glycines cyst counts & Wet-sieving and decanting & Cysts per $100 \mathrm{~cm}^{3}$ soil & Gerdemann (7) \\
\hline Soluble salts & Fixed-ratio extraction & $\mathrm{mMHO}$ per $\mathrm{cm}$ & Carter (5) \\
\hline Organic matter & Loss of weight on ignition & $\%$ & Ball (3) \\
\hline \multirow[t]{2}{*}{$\mathrm{P}$} & Acid ammonium fluoride & & \\
\hline & extraction (Bray P1) & ppm & Carter (5) \\
\hline $\mathrm{K}, \mathrm{Ca}, \mathrm{Mg}$ & Ammonium acetate extraction & ppm & Carter (5) \\
\hline $\mathrm{Mn}, \mathrm{Fe}$ & DPTA extraction & $\mathrm{ppm}$ & Carter (5) \\
\hline \multirow[t]{2}{*}{ Soil moisture } & In situ measurement with Rapitest & & \\
\hline & AGB21 soil moisture meter & Relative scale: 0 (dry) to 10 (wet) & \\
\hline Soil strength & $\begin{array}{r}\text { In situ measurement } \\
\text { with soil cone penetrometer }\end{array}$ & $\begin{array}{l}\text { Relative scale: } 0 \text { (no compaction) } \\
\text { to } 100 \text { (maximal compaction) }\end{array}$ & $\begin{array}{r}\text { American Society of } \\
\text { Agricultural Engineers (2) }\end{array}$ \\
\hline
\end{tabular}


brary; the results were confirmed using forward selection and backward elimination algorithms.

\section{RESULTS}

All fields sampled had high to very high levels of soil fertility (Table 1), typical of the high-yield soybean production environment of Iowa.

Foliar severity of sudden death syndrome ranged from 0 to $100 \%$ along the sampling transects, with disease severity being lower in 1996 than in 1995. Visual inspection of the plots against location along the transect revealed a close, positive association between population densities of $F$. solani f. sp. glycines and disease severity (Fig. 2). There was a weak, positive relationship between $H$. glycines cyst counts and disease for the field shown in Figure 2, while other soil variables displayed no apparent associations with disease along the transects.

Cross-correlation analysis confirmed the visual observations from the scatter plots that only the two biological soil factors $(F$. solani f. sp. glycines population densities and $H$. glycines cyst counts) showed consistent associations (having the same sign of the correlation coefficient) with disease severity across all fields (Table 3); however, the cross-correlation coefficients for $H$. glycines were not always statistically significant. Chemical soil variables were significantly associated with disease in some fields, but the cross-correlation coefficients often changed signs between fields (Table 3). For example, available $\mathrm{K}$ was significantly correlated with disease severity in five fields, with the coefficient being negative in one field $(r=-0.575)$ and positive in four fields ( $r=0.376$ to 0.766 ). Closer inspection revealed that the magnitude and signs of the cross-correlation coefficients were dependent on the overall $\mathrm{K}$-concentrations in the fields. As the median K-concentration increased, the crosscorrelation coefficient between $\mathrm{K}$ and disease along the transect decreased (Fig. 4). Other chemical soil variables (organic matter, $\mathrm{P}$, and $\mathrm{Mn}$ ) also had significant cross-correlation coefficients that changed signs among fields (Table 3), but for these variables there was no relation between their mean or median levels in the field and the magnitude and signs of the cross-correlation coefficients (data not shown). Soil strength and soil moisture, the two physical soil factors in the analysis, showed significant associations with disease severity in three and two out of seven fields, respectively (Table 3 ); all significant correlations were positive for soil moisture and negative for soil strength, indicating that, at the time of assessment, disease was more severe in moister, less compacted sections along the transects.

When data from all fields were combined and examined using stepwise discriminant analysis (Table 4), F. solani f. sp. glycines population densities, $H$. glycines cyst counts, and K-concentrations were significantly greater in soil samples from areas with medium to severe disease

Foliar disease severity (\%)
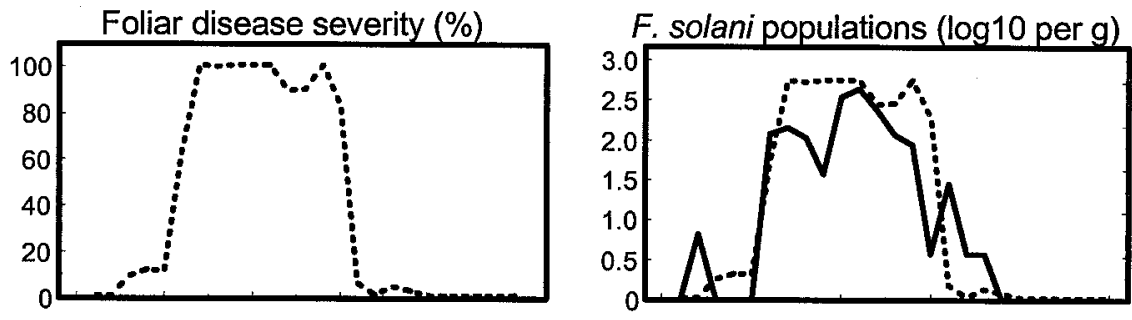

H. glycines cyst counts (per $100 \mathrm{cc}$ )
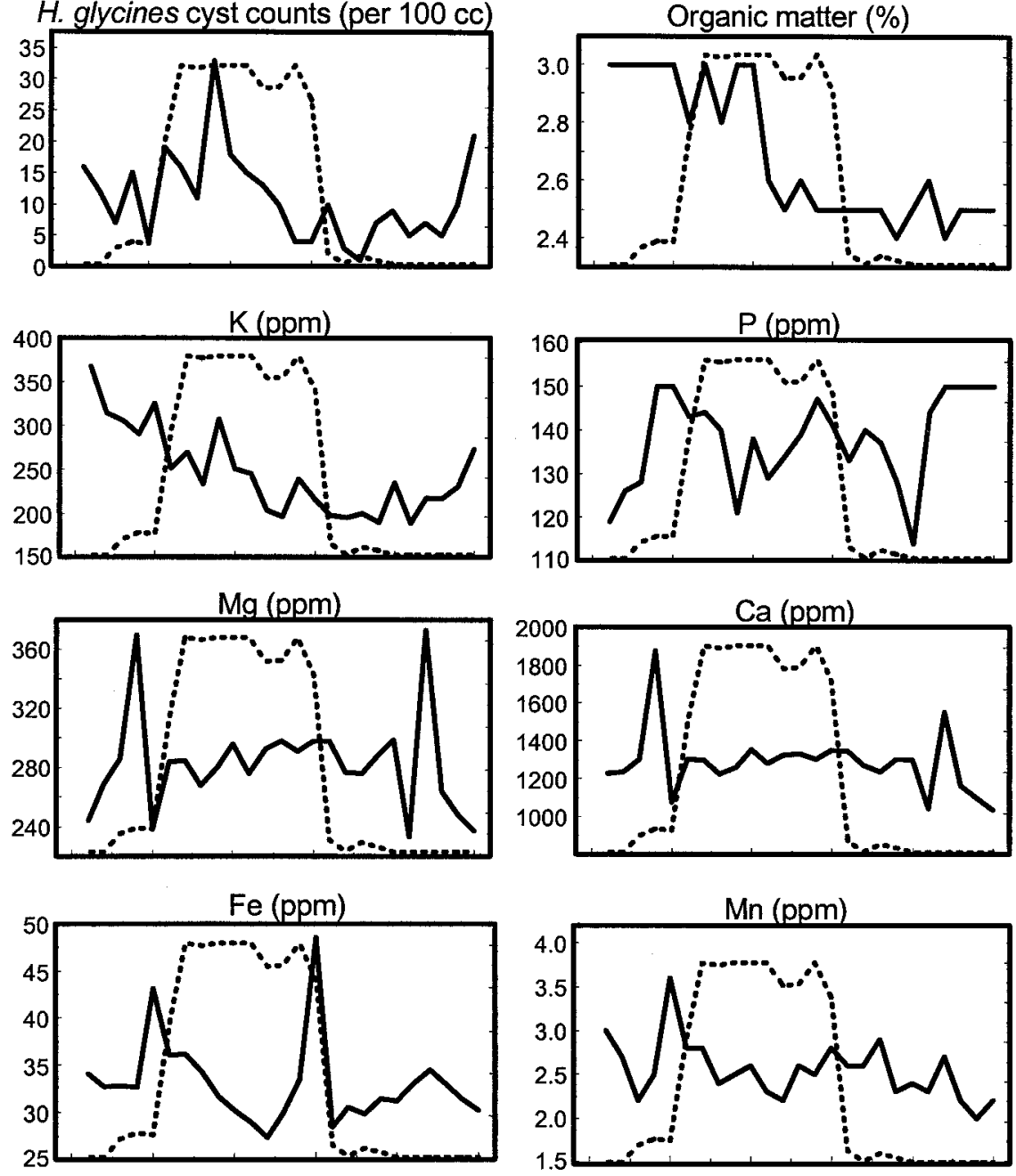

Relative soil moisture (scale 0-10)

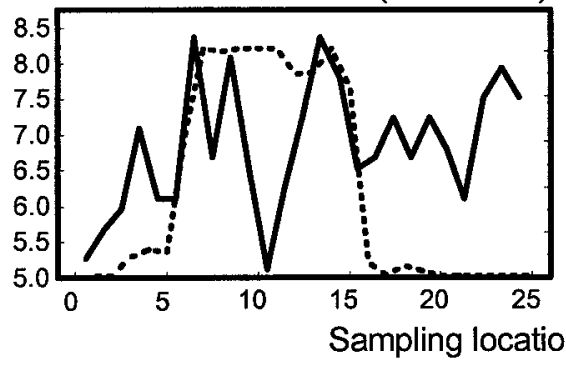

Relative soil strength (scale 0-100)

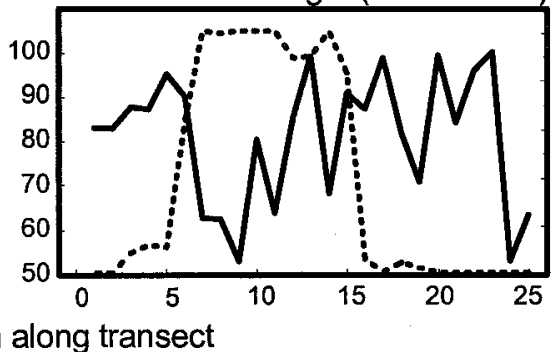

Fig. 2. Variations in foliar disease severity (dashed lines) and biological, chemical, and physical soil characteristics (solid lines) along a transect through an area with sudden death syndrome in a commercial soybean field in east-central Iowa (field 2 in Table 1). Note the close, positive association between population densities of Fusarium solani f. sp. glycines and disease severity along the transect. 
(partial $\left.R^{2}=0.4953\right)$, while $\mathrm{K}\left(\right.$ partial $R^{2}=$ 0.0674 ) and $H$. glycines cyst counts (partial $R^{2}=0.0277$ ) showed very minor (but statistically significant) effects. None of the other soil variables were associated with disease across all fields. The same results were obtained when forward selection or backward elimination algorithms were used instead of the stepwise selection algorithm (data not shown).

\section{DISCUSSION}

This study indicated that two biological soil variables ( $F$. solani f. sp. glycines population densities and, to a lesser extent, $H$. glycines cyst counts) were positively associated with severity of sudden death syndrome in the high-yield soybean production environment of Iowa. This result was consistent with both methods of analysis (univariate and multivariate) for all nine fields sampled during 2 years in two geographical regions of the state (central and east-central Iowa); fields in other parts of
Iowa were not included because sudden death syndrome was not found there (31). Available K was identified as a possible disease-enhancing factor, but the magnitude of the effect was dependent on the overall K-concentrations in the fields. None of the other chemical and physical soil variables examined showed consistent associations with disease severity across all fields. Some variables correlated significantly with disease in individual fields, but the signs of the correlation coefficients often changed between fields. Such inconsistencies are not uncommon in the analysis of complex multivariate data sets, such as those involving multiple soil variables, due to intercorrelation among individual variables and associated redundancy problems (1). For example, Workneh et al. (29) showed that redundancy resulting from intercorrelation among soil variables resulted in changing signs of the correlation coefficients in the analysis of soil factors associated with

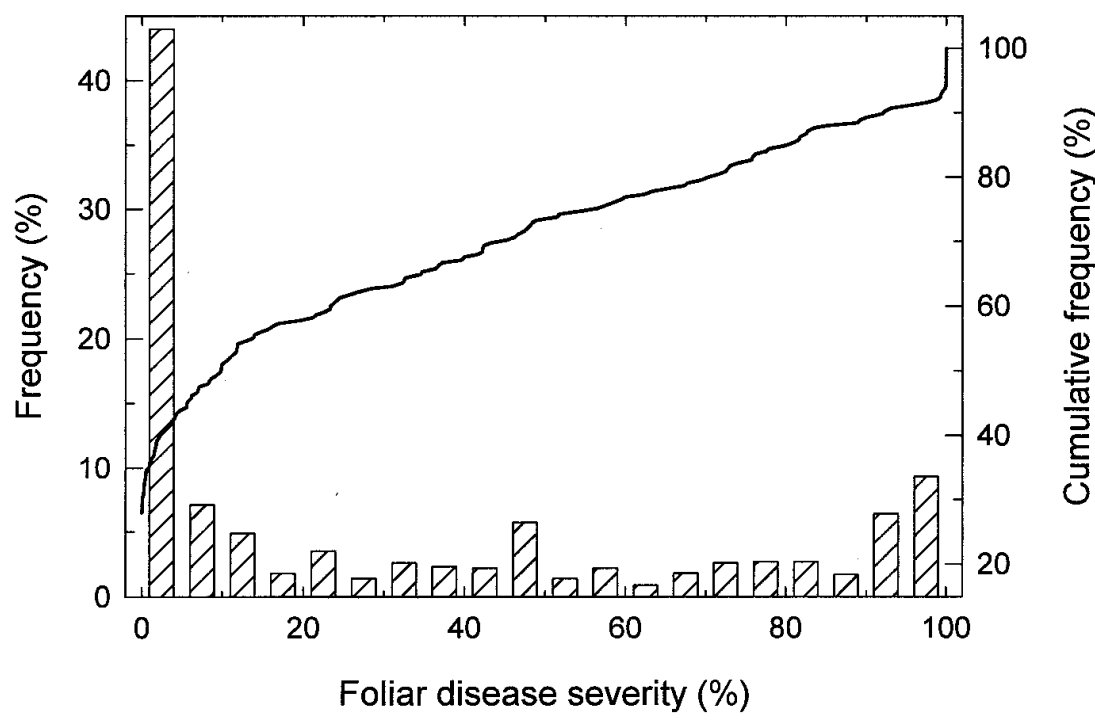

Fig. 3. Frequency distribution (vertical bars) and cumulative frequency distribution (solid line) of foliar disease severity along transects through areas with sudden death syndrome in commercial soybean fields $(N=225)$.

root disease intensity in commercial tomato fields.

Gray and Achenbach (8) and Rupe et al. (22) demonstrated the effects of $F$. solani $\mathrm{f}$. sp. glycines inoculum density on severity of sudden death syndrome in greenhouse and experimental field plot conditions, respectively. However, to our knowledge, this is the first report to establish associations between population densities of the pathogen in commercial field soils and disease severity. To more clearly demonstrate a causal relationship between $F$. solani f. sp. glycines population densities and disease, soil samples should be collected at multiple times, including spring and early summer when $F$. solani f. sp. glycines colonizes and infects roots of soybean seedlings (19). This was not practical in our study because the low prevalence of the disease in Iowa (31), together with strong annual variations in disease severity and the patchy distribution of diseased plants in affected fields, eliminated the possibility of sampling before symptoms of the disease became apparent several months after planting. Nevertheless, we surmise that the assumption of a causal relationship (greater population densities in the soil cause more severe symptoms) rather than an a posteriori association (affected plants harbor greater populations of the pathogen) is warranted. Support for this assertion comes from a 4-year population study of $F$. solani $\mathrm{f}$. sp. glycines in commercial field plots in Arkansas (22), which showed that population densities of the pathogen in infested soil remained constant from planting to growth stage R6, followed by a significant increase before or at harvest. These results suggest that $F$. solani f. sp. glycines population densities measured at growth stage R6 (as done in our study) accurately represent those at planting, thus strengthening the case for a causal relationship between inoculum density and disease. Further, there were no associations between any of the soil variables and $F$. solani f. sp. glycines population densities (the closest correlation was

Table 3. Cross-correlation coefficients ${ }^{\mathrm{a}}$ between biological, chemical, and physical soil variables and foliar disease severity (angular-transformed) along transects through areas with sudden death syndrome in commercial soybean fields

\begin{tabular}{|c|c|c|c|c|c|c|c|c|c|c|c|c|}
\hline Field $^{b}$ & $\begin{array}{l}\text { F. solani f. } \\
\text { sp. } \text { glycines }^{\mathrm{c}}\end{array}$ & $\begin{array}{l}H . \\
\text { glycines }^{\mathrm{d}}\end{array}$ & $\begin{array}{c}\text { Soluble } \\
\text { salts }\end{array}$ & $\begin{array}{l}\text { Organic } \\
\text { matter }\end{array}$ & $\mathbf{P}$ & $\mathbf{K}$ & Ca & Mg & Mn & $\mathbf{F e}$ & $\begin{array}{c}\text { Soil } \\
\text { moisture }\end{array}$ & $\begin{array}{c}\text { Soil } \\
\text { strength }\end{array}$ \\
\hline 1 & $0.784 *$ & 0.354 & -0.046 & -0.140 & $-0.428 *$ & 0.257 & -0.074 & -0.076 & $-0.386 *$ & $e^{e}$ & -0.006 & $-0.384 *$ \\
\hline 2 & $0.875 *$ & $0.387 *$ & $\ldots$ & 0.241 & -0.030 & -0.015 & 0.145 & 0.129 & 0.027 & 0.074 & 0.211 & $-0.387 *$ \\
\hline 3 & $0.635 *$ & 0.240 & $\ldots$ & $-0.671 *$ & 0.017 & $-0.575 *$ & 0.025 & 0.030 & $-0.636 *$ & . & -0.024 & -0.097 \\
\hline 4 & $0.652 *$ & $0.596 *$ & & $0.664 *$ & $0.816 *$ & $0.766 *$ & -0.074 & $-0.561 *$ & $0.634 *$ & & $0.390 *$ & 0.221 \\
\hline 5 & $0.721 *$ & 0.128 & $0.672 *$ & 0.183 & $0.550 *$ & $0.582 *$ & -0.074 & 0.018 & -0.268 & & $\ldots$ & $\ldots$ \\
\hline 6 & $0.830 *$ & 0.331 & & $0.482 *$ & 0.000 & -0.243 & $0.528 *$ & -0.050 & 0.007 & -0.288 & & \\
\hline 7 & $0.748 *$ & $0.443 *$ & 0.052 & 0.059 & 0.168 & $0.376 *$ & 0.025 & 0.173 & -0.342 & -0.344 & $0.593 *$ & -0.006 \\
\hline 8 & $0.869 *$ & $0.399 *$ & -0.144 & $-0.442 *$ & $0.637 *$ & $0.601 *$ & -0.047 & -0.229 & -0.347 & 0.081 & 0.206 & -0.240 \\
\hline 9 & $0.883 *$ & $0.495 *$ & $0.623 *$ & $-0.689 *$ & -0.310 & 0.039 & -0.283 & -0.090 & $-0.752 *$ & $-0.619 *$ & 0.027 & $-0.503 *$ \\
\hline
\end{tabular}

${ }^{a}$ Values followed by an asterisk are statistically significant $(P \leq 0.05)$

b Table 1 describes the fields.

${ }^{\mathrm{c}}$ Fusarium solani f. sp. glycines populations. Population densities were log-transformed.

${ }^{\mathrm{d}}$ Heterodera glycines cyst counts.

e Not determined. 
with organic matter, $r=0.206$ ), suggesting that $F$. solani $\mathrm{f}$. sp. glycines was the single most important factor and presumably had a direct effect on disease severity.

Previous research in southern soybean production regions of the United States, where soil fertility and yield potential are lower, indicated that $H$. glycines can enhance severity of sudden death syndrome $(14,15,17,18)$; this result was confirmed in our study for North-Central field conditions. However, the relationships of chemical and physical soil variables to disease severity in the field have not been studied in detail previously. An exception is the work by Rupe et al. (23), in which multiple regression analysis was used to relate the levels of various plant nutrients to foliar severity of sudden death syndrome in an experimental field in Arkansas at soybean growth stage R2. The authors reported that increased concentrations of $\mathrm{P}$, soluble salts, organic matter, and exchangeable $\mathrm{Na}, \mathrm{Ca}$, and $\mathrm{Mg}$ tended to be associated with more severe disease, but only soluble salts and $\mathrm{P}$ consistently appeared as predictors in all their regression models. $H$. glycines counts (second-stage juveniles) were not consistently associated with disease in their analysis, and soil population densities of $F$. solani f. sp. glycines were not determined because the research reported in their study was done before the causal agent of sudden death syndrome had been identified. Based on these results, the authors concluded that increased levels of soil fertility and more favorable production environments favored the disease. Because the field sampled by Rupe et al. (23) had only low to adequate levels of soil fertility, their results cannot be compared directly to those of our study, in which most fields had high or very high nutrient levels. Nevertheless, our analysis did suggest that increased soil fertility (increased K-concentrations) along the sampling transects tended to enhance sudden death syndrome in some fields.

Results from the cross-correlation analyses indicated that disease in some fields was more severe in moister, less compacted sections along the transects, which is also consistent with the hypothesis of more favorable production environments favoring the disease $(15,18)$. However, caution must be exercised when interpreting the role of soil strength and soil moisture because these two physical factors may have varied considerably during the growing season; thus, a single measurement in time is unlikely to give an accurate representations of the soil environment encountered from planting to growth stage R6.

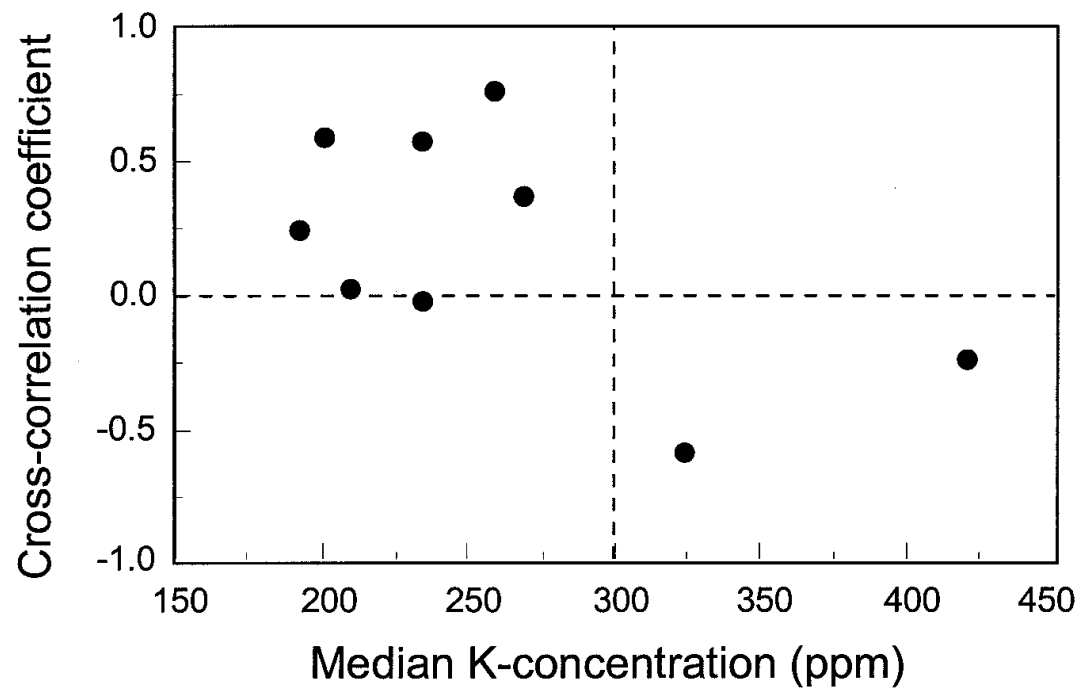

Fig. 4. Cross-correlation coefficients between available potassium $(\mathrm{K})$ and foliar disease severity (angular-transformed) along transects through areas with sudden death syndrome in commercial soybean fields, plotted against median K-concentration.

Table 4. Variables contributing significantly to classification of soil samples $(N=225)$ into sudden death severity classes ${ }^{\mathrm{a}}$ by stepwise discriminant analysis, based on transect sampling through areas with sudden death syndrome in nine commercial soybean fields

\begin{tabular}{|c|c|c|c|c|}
\hline Variable & $P>F$ & Partial $R^{2}$ & $\begin{array}{c}\text { Cumulative } \\
\text { ASCC }^{\mathbf{b}}\end{array}$ & $P>\mathrm{ASCC}$ \\
\hline Fusarium solani f. sp. glycines populations ${ }^{\mathrm{c}}$ & 0.0001 & 0.4953 & 0.4953 & 0.0001 \\
\hline $\mathrm{K}$ & 0.0001 & 0.0674 & 0.5293 & 0.0001 \\
\hline Heterodera glycines cyst counts & 0.0127 & 0.0277 & 0.5424 & 0.0001 \\
\hline
\end{tabular}

a Samples were categorized into two groups according to foliar disease severity (percent chlorotic or necrotic leaf area): no or little disease $(<10 \%)$ and moderate to severe disease $(\geq 10 \%)$.

${ }^{b}$ ASCC $=$ average squared canonical correlation .

c Population densities were log-transformed.

From a production viewpoint, our results suggest that the localized presence or absence of $F$. solani $\mathrm{f}$. sp. glycines is the chief reason for the patchiness of sudden death syndrome in affected fields. Thus, manipulation of soil nutrient status or fertility level appears to have limited potential for reducing disease in the high-yield soybean production environment of Iowa. Instead, soybean producers should focus on preventing the establishment or reducing populations of $F$. solani f. sp. glycines and $H$. glycines in their fields. In this context, our results are important for ongoing risk assessment studies of sudden death syndrome. The disease has only recently emerged as a problem in the northern part of the soybean belt in the United States $(9,13,31,32)$, although it has been an important constraint to soybean production in the southern states for more than 20 years $(18,21)$. It is not known whether $F$. solani f. sp. glycines has only recently been introduced into the northern production areas, or whether the disease has been present there without being recognized. Based on the expansion of the geographical range of sudden death syndrome and the losses associated with this disease, there is concern among producers in the North-Central region that the disease may become a significant production problem there. Thus, regional risk assessment studies are needed to determine if and where environmental conditions are suitable for regular occurrence of the disease, and more information is needed on relationships between soil factors, environmental conditions, and disease development. In a previous study, we developed simple models for the effects of soil temperature and soil moisture on development of sudden death syndrome (25). The present study extends this work by establishing correlations between additional soil factors and disease. Taken together, these two studies suggest that sudden death syndrome can occur in a wide range of soils (Table 1), determined chiefly by the presence of $F$. solani $\mathrm{f}$. sp. glycines and favorable soil temperature and moisture conditions, rather than by other biological, chemical, or physical soil variables. Based on these results, it should be practical to use long-term temperature data and regional soil moisture maps, perhaps in combination with maps of $H$. glycines distribution, to assess the risk that sudden death syndrome will become a problem in previously unaffected production areas (26).

\section{ACKNOWLEDGMENTS}

We thank R. Johnson and C. Peters for technical assistance.

\section{LITERATURE CITED}

1. Afifi, A. A., and Clark, V. 1990. ComputerAided Multivariate Analysis, 2nd Edition. Van Nostrand Reinhold, New York.

2. American Society of Agricultural Engineers. 1993. Soil cone penetrometer. ASAE Standard S313.2. American Society of Agricultural Engineers, St. Joseph, MI. 
3. Ball, D. F. 1964. Loss-on-ignition as an estimate of organic matter and organic carbon in non-calcareous soils. J. Soil Sci. 15:84-92.

4. Brocklebank, J. C., and Dickey, D. A. 1986. SAS System for Forecasting Time Series, 1986 Edition. SAS Institute Inc., Cary, NC.

5. Carter, M. R., ed. 1993. Soil Sampling and Methods of Analysis. Lewis Publishers, Boca Raton, FL.

6. Fehr, W. R., Caviness, C. E., Burmood, D. T., and Pennington, J. S. 1971. Stage of development descriptions for soybeans, Glycine $\max ($ L.) Merrill. Crop Sci. 11:929-931.

7. Gerdemann, J. W. 1955. Relation of a large soil-borne spore to phycomycetous mycorrhizal infections. Mycologia 47:619-632.

8. Gray, L. E., and Achenbach, L. A. 1996. Severity of foliar symptoms and root and crown rot of soybean inoculated with various isolates and inoculum rates of Fusarium solani. Plant Dis. 80:1197-1199.

9. Hartman, G. L., Noel, G. R., and Gray, L. E. 1995. Occurrence of soybean sudden death syndrome in east-central Illinois and associated yield losses. Plant Dis. 79:314-318.

10. Hershman, D. E., Hendrix, J. W., Stuckey, R. E., and Bachi, P. R. 1990. Influence of planting date and cultivar on soybean sudden death syndrome in Kentucky. Plant Dis. 74:761766.

11. Hirrel, M. C. 1985. Sudden death syndrome: assessment of cause and severity. Proc. Southern Soybean Dis. Workers 12th, Birmingham, AL

12. Horsfall, J. G., and Barratt, R. W. 1945. An improved grading system for measuring plant disease. (Abstr.) Phytopathology 35:655.

13. Jardine, D. J., and Rupe, J. C. 1993. First report of sudden death syndrome of soybeans caused by Fusarium solani in Kansas. Plant Dis. 77:1264.

14. McLean, K. S., and Lawrence, G. W. 1993. Interrelationship of Heterodera glycines and
Fusarium solani in sudden death syndrome of soybean. J. Nematol. 25:434-439.

15. Melgar, J., Roy, K. W., and Abney, T. S. 1994. Sudden death syndrome of soybean: etiology, symptomatology, and effects of irrigation and Heterodera glycines on incidence and severity under field conditions. Can. J. Bot. 72:16471653.

16. Roy, K. W. 1997. Fusarium solani on soybean roots: Nomenclature of the causal agent of sudden death syndrome and identity and relevance of F. solani form B. Plant Dis. 81:259266.

17. Roy, K. W., Lawrence, G. W., Hodges, H. H., McLean, K. S., and Killebrew, J. F. 1989. Sudden death syndrome of soybean: Fusarium solani as incitant and relation of Heterodera glycines to disease severity. Phytopathology 79:191-197.

18. Roy, K. W., Rupe, J. C., Hershman, D. E., and Abney, T. S. 1997. Sudden death syndrome of soybean. Plant Dis. 81:1100-1111.

19. Rupe, J. C. 1988. Relationship of cultivar susceptibility, Fusarium solani, and soybean cyst nematode to soybean sudden death syndrome (SDS). (Abstr.) Phytopathology 78:1545.

20. Rupe, J. C. 1989. Frequency and pathogenicity of Fusarium solani recovered from soybeans with sudden death syndrome. Plant Dis. 73:581-584.

21. Rupe, J. C., Hirrell, M. C., and Hershman, D. E. 1989. Sudden death syndrome. Pages 84 85 in: Compendium of Soybean Diseases, 3rd ed. J. B. Sinclair and P. A. Backman, eds. APS Press, St. Paul, MN.

22. Rupe, J. C., Robbins, R. T., and Gbur, E. E. Jr. 1997. Effect of crop rotation on soil population densities of Fusarium solani and Heterodera glycines and on the development of sudden death syndrome of soybean. Crop Prot. 16:575-580.

23. Rupe, J. C., Sabbe, W. E., Robbins, R. T., and
Gbur, E. E. Jr. 1993. Soil and plant factors associated with sudden death syndrome of soybean. J. Prod. Agric. 6:218-221.

24. Scherm, H., and van Bruggen, A. H. C. 1994 Weather variables associated with infection of lettuce by downy mildew (Bremia lactucae) in coastal California. Phytopathology 84:860 865.

25. Scherm, H., and Yang, X. B. 1996. Development of sudden death syndrome of soybean in relation to soil temperature and soil water matric potential. Phytopathology 86:642-649.

26. Scherm, H., and Yang, X. B. 1997. Risk assessment for sudden death syndrome of soybean in the North-Central United States. (Abstr.) Phytopathology 87 (Suppl.):S86.

27. Scherm, H., Yang, X. B., and Lundeen, P. 1996. Relationship of soil factors to severity of sudden death syndrome of soybean in Iowa. (Abstr.) Phytopathology 86 (Suppl.):S84

28. von Qualen, R. H., Abney, T. S., Huber, D. M., and Schreiber, M. M. 1989. Effects of rotation, tillage, and fumigation on premature dying of soybeans. Plant Dis. 73:740-744.

29. Workneh, F., van Bruggen, A. H. C., Drinkwater, L. E., and Shennan, C. 1993. Variables associated with corky root and Phytophthora root rot of tomatoes in organic and conventional farms. Phytopathology 83:581-589.

30. Wrather, J. A., Kendig, S. R., Anand, S. C. Niblack, T. L., and Smith, G. S. 1995. Effects of tillage, cultivar, and planting date on percentage of soybean leaves with symptoms of sudden death syndrome. Plant Dis. 79:560 562.

31. Yang, X. B., and Lundeen, P. 1997. Occurrence and distribution of soybean sudden death syndrome in Iowa. Plant Dis. 81:719722.

32. Yang, X. B., and Rizvi, S. S. A. 1994. First report of sudden death syndrome of soybean in Iowa. Plant Dis. 78:830. 